\title{
Osmotic Adjustment and the Growth Response of Seven Vegetable Crops following Water-deficit Stress
}

\author{
Stan D. Wullschleger \\ Environmental Sciences Division, P. O. Box 2008, Oak Ridge National \\ Laboratory, Oak Ridge, TN 37831-6034

\section{Derrick M. Oosterhuis} \\ Altheimer Laboratory, Department of Agronomy, University of Arkansas, \\ Fayetteville, AR 72701
}

Additional index words. Abelmoschus esculentus, Beta vulgaris, Capsicum annuum, drought tolerance, leaf growth, Lycopersicon esculentum, osmotic potential, Phaseolus vulgaris, Pisum sativum, Sorghum bicolor, Spinacia oleracea

\begin{abstract}
Growth-chamber studies were conducted to examine the ability of seven vegetable crops-'Blue Lake' bean (Phaseolus vulgaris L.), 'Detroit Dark Red' beet (Beta vulgaris L.), 'Burgundy' okra (Abelmoschus esculentus (Moench), 'Little Marvel' pea (Pisum sativum L.), 'California Wonder' bell pepper (Capsicum annuum L.), 'New Zealand' spinach (Spinacia oleracea L.), and 'Beefsteak' tomato (Lycopersicon esculentum Mill.)-to adjust osmotically in response to water-deficit stress. Water stress was imposed by withholding water for 3 days, and the adjustment of leaf and root osmotic potentials upon relief of the stress and rehydration were monitored with thermocouple psychrometers. Despite similar reductions in leaf water potential and stomata1 conductance among the species studied, crop-specific differences were observed in leaf and root osmotic adjustment. Leaf osmotic adjustment was observed for bean, pepper, and tomato following water-deficit stress. Root osmotic adjustment was significant in bean, okra, pea, and tomato. Furthermore, differences in leaf and root osmotic adjustment were also observed among five tomato cultivars. Leaf osmotic adjustment was not associated with the maintenance of leaf growth following water-deficit stress, since leaf expansion of water-stressed bean and pepper, two species capable of osmotic adjustment, was similar to that of spinach, which exhibited no leaf osmotic adjustment.
\end{abstract}

Osmotic adjustment has been suggested as a mechanism of drought tolerance whereby

\footnotetext{
Received for publication 15 Nov. 1990. Research sponsored by the Arkansas Agricultural Experiment Station. The senior author was supported in part by the Alexander Hollaender Distinguished Postdoctoral Fellowship Program provided by the U.S. Dept. of Energy, Office of Health and Environmental Research, and administered by Oak Ridge Associated Universities. Publication no. 3738, Environmental Sciences Division, Oak Ridge National Laboratory. Oak Ridge National Laboratory is managed by Martin Marietta Energy Systems, Inc., under contract DE-AC05-84OR21400 with the U.S. Dept. of Energy. The cost of publishing this paper was defrayed in part by the payment of page charges. Under postal regulations, this paper therefore must be hereby marked $a d$ -
} vertisement solely to indicate this fact. plants achieve either a survival or a productivity advantage under conditions of water shortage (Ludlow and Muchow, 1988; Turner, 1981; Wright et al., 1983). Lowered osmotic potential in response to water-deficit stress is proposed to play a significant role in turgor maintenance (Zimmermann, 1978), thereby regulating plant growth processes (Morgan, 1984; Turner, 1986). However, although osmotic adjustment has been implemented as a selection criterion for improved drought hardiness (Morgan, 1983), the importance of osmotic adjustment in maintaining leaf and root growth during waterdeficit stress remains controversial (Munns, 1988).

Continued leaf expansion during decreasing leaf water potential has been used to demonstrate the adaptive significance of osmotic adjustment. Toft et al. (1987) reported that leaf osmotic adjustment in the East African grass Eustachys paspaloides (Vahl) Lanza \& Mattei in response to periodic waterdeficit stress was related to a rapid recovery in leaf growth upon rewatering. Recently, West et al. (1990) observed significant osmotic adjustment in young, meristematic, and elongating regions of Festuca arundinacea Schreb. and speculated that lowered osmotic potentials and turgor maintenance in these tissues favored continued leaf growth and tiller survival during intermittent drought. Further, lower osmotic potential also may be responsible for stomatal adjustment, a process that enables stomata to remain open at progressively lower leaf water potentials (Ludlow et al., 1985; Oosterhuis and Wullschleger, 1987).

Crop-water relations of vegetable species have been investigated with particular emphasis on the physiological processes affected by water-deficit stress (Hsiao, 1973; Santakumari and Berkowitz, 1989; Weisz et al., 1989). However, few studies have addressed osmotic adjustment in vegetable crops (Fanjul and Rosher, 1984; Levitt, 1985) and no studies were found that examined the relationship between osmotic adjustment and growth maintenance for species exhibiting this drought-tolerance trait. The objectives of this study, therefore, were to a) investigate leaf and root osmotic adjustment of seven vegetable crops in response to water-deficit stress, and b) evaluate the potential growth advantage associated with this trait during recovery from water-deficit stress. Sorghum [Sorghum bicolor (L.) Moench] was included for comparison because it exhibits considerable osmotic adjustment (Ackerson et al., 1980).

Seven vegetable crops-'Blue Lake' bean, 'Detroit Dark Red' beet, 'Burgundy' okra, 'Little Marvel' pea, 'California Wonder' bell pepper, 'New Zealand' spinach, and 'Beefsteak' tomato were grown individually in 0.35 -liter containers in a fine-mixtured sand. Seedlings were grown in a controlled-environment chamber equipped with fluorescent tubes supplemented by $60-\mathrm{W}$ incandescent bulbs. The 14-h daylight regime had a photosynthetically active radiation of 375 $\mu \mathrm{mol} \cdot \mathrm{m}^{-2} \cdot \mathrm{s}^{-1}$ and a day/night cycle of $28 /$ 23C. All seedlings were watered daily with half-strength Hoagland's nutrient solution (Hoagland and Arnon, 1950). 


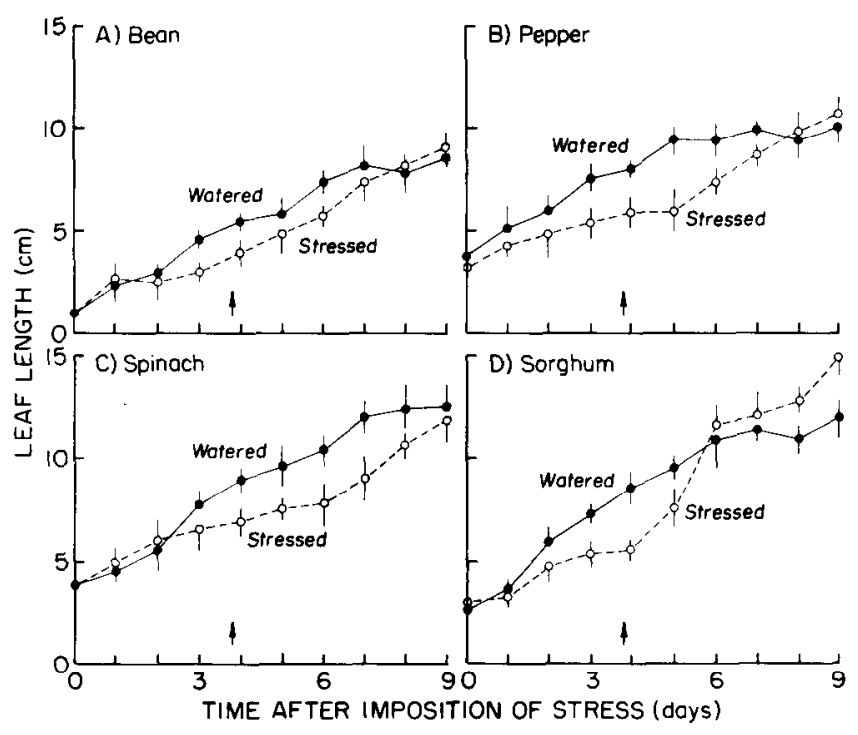

Fig. 1. Leaf growth response of bean, pepper, spinach, and sorghum during and after imposed waterdeficit stress. Arrows indicate when water-stressed plants were rewatered and thereafter maintained well-watered. Vertical bars represent $\pm \mathrm{SE}$.

Table 1. Osmotic potentials for the leaves and roots of seven vegetable crops in response to waterdeficit stress. Data for sorghum are shown for comparison.

\begin{tabular}{lcccccc}
\hline & \multicolumn{5}{c}{ Osmotic potential (MPa) } \\
\cline { 2 - 7 } Crop & Leaves & & & Roots & \\
\cline { 2 - 7 } \cline { 3 - 7 } & Control & Stressed & $P>F^{*}$ & Control & Stressed & $P>\mathrm{F}$ \\
Bean & -1.53 & -1.71 & $*$ & -0.56 & -0.63 & $*$ \\
Okra & -1.08 & -1.13 & NS & -0.59 & -0.61 & NS \\
Pea & -1.09 & -1.16 & NS & -0.59 & -0.65 & $*$ \\
Pepper & -1.29 & -1.31 & NS & -0.65 & -0.71 & $*$ \\
Sorghum & -1.36 & -1.57 & $* *$ & -0.61 & -0.63 & NS \\
Spinach & -1.93 & -2.24 & $* *$ & -0.41 & -0.60 & $* *$ \\
Tomato & -1.08 & -1.11 & NS & -0.59 & -0.62 & NS \\
\hline
\end{tabular}

${ }^{2}$ Significance of $\mathrm{F}$ test for water-stress effects within crops.

$* * *$ Ns Significant at $P=0.01$ or 0.05 or nonsignificant, respectively.

Table 2. Osmotic potentials for the leaves and roots of selected tomato cultivars in response to waterdeficit stress.

\begin{tabular}{|c|c|c|c|c|c|c|}
\hline \multirow[b]{3}{*}{ Cultivar } & \multicolumn{6}{|c|}{ Osmotic potential (MPa) } \\
\hline & \multicolumn{3}{|c|}{ Leaves } & \multicolumn{3}{|c|}{ Roots } \\
\hline & Control & Stressed & $P>\mathrm{F}^{\mathrm{z}}$ & Control & Stressed & $P>\mathrm{F}$ \\
\hline Beefsteak & -0.79 & -0.90 & $*$ & -0.65 & -0.71 & $*$ \\
\hline Yellow pear & -0.89 & -0.99 & $*$ & -0.64 & -0.66 & NS \\
\hline Homestead & -0.78 & -0.84 & NS & -0.68 & -0.69 & NS \\
\hline Roma VF & -0.70 & -0.80 & * & -0.70 & -0.73 & NS \\
\hline Hybrid cherry & -0.86 & -0.89 & NS & -0.68 & -0.72 & NS \\
\hline
\end{tabular}

${ }^{2}$ Significance of $\mathrm{F}$ test for water-stress effects within cultivars.

****NSSignificant at $P=0.01$ or 0.05 or nonsignificant, respectively.

Thirty-five-day-old plants were waterstressed by withholding nutrient solution from the pots for 3 days. During this period, wellwatered plants received tap water to minimize potential nutrient differences between treatments. Stomata1 conductance of the abaxial leaf surface was determined with an LI-1600 steady state porometer (LI-COR, Lincoln, Neb.). Relative water content (RWC) was measured using the relative turgidity technique of Weatherley (1950) on ten 1-cmdiameter leaf disks floated on distilled water for $4 \mathrm{~h}$. All measurements were made on uppermost fully expanded leaves. Leaf growth was monitored for selected species using daily measurements of leaf length, beginning when the water-stress treatment was imposed and continuing for 6 days after rewatering.

When the water-stress treatment was terminated, stomatal conductance for all species was reduced by at least $70 \%$ compared with the controls. Subsequently, plants were rewatered, placed in aerated nutrient solution, and rehydrated overnight (> $12 \mathrm{~h}$ ). This procedure was sufficient to increase the RWC of water-stressed leaves from $<75 \%$ to $>88 \%$. The following morning, leaf and root water, osmotic, and turgor potentials were measured. Components of leaf water potential were measured on 0.9 -cm-diameter disks with end-window thermocouple psychrometers (Merrill Specialty Equipment, Logan, Utah, model 84-1VC), and root components were measured with screen-caged thermocouple psychrometers (model 74-1VC). Root samples were obtained by inverting the pot and carefully removing the root system. Portions of the root system were shaken to remove the sand and gently blotted dry before being placed in the psychrometer-sample chamber. A randomized complete block design with five replications was used and all experiments were repeated twice. Individual contrasts $(1 \mathrm{df})$ were used to test for treatment differences in leaf and root osmotic potentials.

Development of water stress among the seven vegetables was relatively uniform, with significant reductions in stomatal conductance and leaf water potential observed late on the 3rd day of stress (data not shown). The severity of the water stress was sufficient to reduce leaf water potentials to at least $-1.7 \mathrm{MPa}$ or lower in all species and to decrease stomatal conductance to $<0.15$ $\mathrm{mol} \cdot \mathrm{m}^{-2} \cdot \mathrm{s}^{-1}$

Measurements of leaf and root osmotic potential after rehydration indicated both species- and tissue-specific differences in osmotic adjustment. Of the seven vegetable crops examined, only bean and tomato showed significant osmotic adjustment of both leaves and roots (Table 1). Leaf and root osmotic potentials for tomato decreased by $0.16 \mathrm{MPa}$ and $0.10 \mathrm{MPa}$, respectively, with a corresponding percentage adjustment of $12.9 \%$ and $16.4 \%$. Leaf but not root osmotic adjustment was also significant in pepper. Significant root osmotic adjustment alone was observed for okra $(10.2 \%)$ and pea $(9.2 \%)$. Beet and spinach showed no capacity to adjust osmotically in either leaves or roots following water-deficit stress. The magnitude of leaf and root osmotic adjustment for sorghum was $0.31 \mathrm{MPa}(16.1 \%)$ and $0.19 \mathrm{MPa}(46.3 \%)$, respectively.

Differences in osmotic adjustment were also recorded for five cultivars of tomato (Table 2). Significant leaf osmotic adjustment was observed for 'Beefsteak' (13.9\%), 'Yellow pear' $(11.2 \%)$, and 'Roma VF' (14.3\%). The decline in leaf osmotic potentials for these three cultivars averaged $0.10 \mathrm{MPa}$ following water-deficit stress and subsequent rehydration. Root osmotic adjustment was significant only in 'Beefsteak', where osmotic adjustment was $<10 \%$.

Several studies have suggested that osmotic adjustment following water-deficit stress improves cell turgor and subsequently aids in growth recovery (Morgan, 1984; Turner, 1986). However, we observed no direct association between osmotic adjustment and post-stress leaf extension (Fig. 1). During the 3 days of water deficit, leaf extension for bean, pepper, spinach, and sorghum was reduced, with significant reductions in leaf length continuing for 2 to 4 days after rewatering. Although leaf extension of previously water-stressed plants increased relative to that of the well-watered controls, no differences were observed between the growth 
of those vegetable crops that exhibited osmotic adjustment (bean and pepper) and those that lacked osmotic adjustment (spinach). In contrast, sorghum, which showed the greatest osmotic adjustment, exhibited a $25 \%$ increase in leaf length 6 days after rewatering. Whether this change reflects an increase in leaf growth due solely to osmotic adjustment is unknown, although osmotic adjustment has been proposed to prolong leaf extension after water-deficit stress in several Gramineous crops, including sorghum (Jones and Turner, 1978).

Turner (1986) speculated that, during waterdeficit stress, low soil water potential may overwhelm any advantage of turgor maintenance and proposed that leaf osmotic adjustment may be effective in maintaining growth only if plants also exhibit root osmotic adjustment. Our results document that some vegetable crops possess a capacity to adjust osmotically in the roots, as well as in the leaves (e.g., bean and tomato). The benefits of this adjustment may be the enhanced ability of selected vegetable species to maintain a favorable water status, particularly in the roots, during water-deficit stress. Prolonged root growth during and after waterdeficit stress would enable plants to exploit a greater soil volume and to maximize soil water extraction. Ludlow and Muchow (1988) have cautioned, however, that although plants exhibiting osmotic adjustment may have an advantage with respect to enhanced soil water extraction, continued water extraction by these plants could exhaust the supply of soil water and contribute to premature soil dehydration.

Research on the mechanisms of drought tolerance and osmotic adjustment has been based on the assumption that turgor maintenance enables increased photosynthesis and leaf growth when plants are exposed to waterdeficit stress (Munns, 1988). However, the origin of solutes that enable a plant to decrease its osmotic potential while simultaneously continuing cell expansion is unclear. Munns (1988) emphasized that the solutes that account for osmotic adjustment must be diverted from growth processes such as protein and cell wall synthesis and, therefore, osmotic adjustment should not necessarily be expected to promote growth. In contrast, Richardson and McCree (1985) have dem- onstrated in grain sorghum that the metabolic cost of storing and using photosynthate for osmotic adjustment was less than the cost of converting it into new biomass.

Finally, although the number of vegetable crops surveyed in this study was small, it appeared that these species generally lacked the degree of osmotic adjustment of sorghum and cotton (Oosterhuis and Wullschleger, 1987). While this observation may be coincidental, such differences in osmotic adjustment could reflect how selection pressures (i.e., breeding dryland vs. irrigated crops) have influenced the mechanisms by which a crop responds to drought. It would be interesting to investigate a more extensive range of vegetable crops for osmotic adjustment between and within species to quantify the genetic variability of this trait. Furthermore, future studies might also consider additional water-stress effects that affect leaf expansion, including alterations in cell wall elasticity and growth threshold potentials, the contribution of osmotic adjustments to the maintenance of protoplast volume, differences in the water-stress response of monocots vs. dicots, and the persistence of the osmotically adjusted condition.

\section{Literature Cited}

Ackerson, R.C., D.R. Kreig, and F.J.M. Sung. 1980. Leaf conductance and osmoregulation of field grown sorghum genotypes. Crop Sci. 20:10-14.

Fanjul, L. and P.H. Rosher. 1984. Effects of water stress on internal water relations of apple leaves. Physiol. Plant. 62:321-328.

Hoagland, D.R. and D.I. Arnon. 1950. The water culture method for growing plants without soil. Calif. Agr. Expt. Sta. Circ. 347.

Hsiao, T.C. 1973. Plant response to water stress. Annu. Rev. Plant Physiol. 24:519-570.

Jones, M.M. and N.C. Turner. 1978. Osmotic adjustment in leaves of sorghum in response to water deficits. Plant Physiol. 61:122-126.

Levitt, J. 1985. Relationship of dehydration rate to drought avoidance, dehydration tolerance and dehydration avoidance of cabbage leaves, and to their acclimation during drought-induced water stress. Plant Cell \& Environ. 8:287-296.

Ludlow, M.M. and R.C. Muchow. 1988. Critical evaluation of the possibilities for modifying crops for high production per unit of precipitation, $\mathrm{p}$. 179-211. In: F.R. Bidinger and C. Johansen (eds.). Drought research priorities for the dry- land tropics. ICRISAT, Patancheru, India.

Ludlow, M.M., M.J. Fisher, and J.R. Wilson. 1985. Stomata1 adjustment to water deficits in three tropical grasses and a tropical legume in controlled conditions and in the field. Austral. J. Plant Physiol. 12:131-149.

Morgan, J.M. 1983. Osmoregulation as a selection criterion for drought tolerance in wheat. Austral. J. Agr. Res. 34:607-614.

Morgan, J.M. 1984. Osmoregulation and water stress in higher plants. Annu. Rev. Plant Physiol. 35:299-319.

Munns, R. 1988. Why measure osmotic adjustment? Austral. J. Plant Physiol. 15:717-726.

Oosterhuis, D.M. and S.D. Wullschleger. 1987. Osmotic adjustment in cotton (Gossypium hirsutum L.) leaves and roots in response to water stress. Plant Physiol. 84:1154-1157.

Richardson, S. and K.J. McCree. 1985. Carbon balance and water relations of sorghum exposed to salt and water stress. Plant Physiol. 79:10151020.

Santakumari, M. and G.A. Berkowitz. 1989. Protoplast volume: water potential relationship and bound water fraction in spinach leaves. Plant Physiol. 91:13-18.

Toft, N.L., S.J. .McNaughton, and N.J. Georgeadis. 1987. Effects of water stress and simulated grazing on leaf elongation and water relations of an East African grass, Eustachys paspaloides. Austral. J. Plant Physiol. 14:211226.

Turner, N.C. 1981. Designing crops for dryland Australia: can the deserts help us? J. Austral. Inst. Agr. Sci. 47:29-34

Turner, N.C. 1986. Adaptation to water deficits: a changing perspective. Austral. J. Plant Physiol. 13:175-190.

Weatherley, P.E. 1950. Studies in the water relations of the cotton plant. I. The field measurement of water deficits in leaves. New Phytol. 48:81-97.

Weisz, P.R., H.C. Randall, and T.R. Sinclair. 1989. Water relations of turgor recovery and restiffening of wilted cabbage leaves in the absence of water uptake. Plant Physiol. 91:433439.

West, C.P., D.M. Oosterhuis, and S.D. Wullschleger. 1990. Osmotic adjustment in tissues of tall fescue in response to water deficit. Environ. Expt. Bot. 30:149-156.

Wright, G.C., R.C.G. Smith, and J.R. McWilliam. 1983. Differences between two grain sorghum genotypes in adaptation to drought stress. I. Crop growth and yield processes. Austral. J. Agr. Res. 34:615-626.

Zimmermann, U. 1978. Physics of turgor and osmoregulation. Annu. Rev. Plant Physiol. 29:122148. 